\title{
Descolonizar os livros didáticos: raça, gênero e colonialidade nos livros de educação do campo*
}

\author{
ROSANA MEDEIROS DE OLIVEIRA
}

Universidade de Brasília, Brasília, DF, Brasil

\section{RESUMO}

Descolonizar o pensamento é uma luta fundamental dos movimentos de educação do campo, é um modo de resistência e re-existência de saberes e modos de vida. Considerando que a subalternização dos saberes do campo é produzida pelo monopólio e visibilidade do saber euro-ocidental, assim como pela desqualificação e invisibilização do saber campesino, este artigo se debruça sobre os livros do Programa Nacional dos Livros Didáticos (PNLD) de educação no campo, atentando para os conhecimentos e modos de vida que ali se apresentam e como se apresentam. Por meio da seleção e análise de acontecimentos imagéticos e textuais significativos, são discutidas hierarquias de saberes e modos de vida nos materiais em questão. $\mathrm{O}$ artigo resulta de uma pesquisa sobre raça e gênero no PNLD de educação no campo, lançado em 2013. Analisando todos os livros do programa, a pesquisa dá a ver dois acontecimentos centrais nos modos em que raça e gênero performam nesses livros: a colonialidade do saber e o estilo politicamente correto.

PALAVRAS-CHAVE

colonialidade; politicamente correto; livro didático; educação do campo.

* Agradeço à Coordenação de Aperfeiçoamento de Pessoal de Nível Superior (CAPES), pela bolsa de pesquisa do Programa Nacional de Pós-Doutorado (PNPDInstitucional), e à Debora Diniz, orientadora do projeto e quem tornou possível esse percurso. 


\title{
DECOLONIZING TEXTBOOKS: RACE, GENDER AND COLONIALITY IN RURAL EDUCATION TEXTBOOKS
}

\begin{abstract}
Decolonizing thought is a fundamental struggle of the movements for rural education. It is a way of resisting and re-iventing knowledge and ways of living. Considering that the monopoly and visibility of western European knowledge devalue, desqualify and invisibilize rural knowledge, this article investigates the books of the Programa Nacional de Livros Didáticos (PNLD) for rural education, seeing how knowledge and ways of life are presented in the textbooks. By means of the selection and analysis of meaningful imagetic and textual events, the article thematizes hierarchies of knowledge and ways of life in the aforementioned textbooks. This article is the result of research about how race and gender are addressed in all the books of the PNLD for rural education, released on 2013. The research reveals two central events regarding the ways by which race and gender are performed on those books: the coloniality of knowledge and the politically correct style.
\end{abstract}

KEYWORDS

coloniality; politically correct; textbook; rural education.

\section{DESCOLONIZAR LOS LIBROS DE TEXTO: RAZA, GÉNERO Y COLONIALIDAD EN LOS LIBROS DE EDUCACIÓN DEL CAMPO}

\section{RESUMEN}

Descolonizar el pensamiento es una lucha fundamental del movimiento de la educación rural, es una forma de resistencia y re-existencia de conocimientos y formas de vida. En vista de que la subordinación de los saberes del campo se produce por el monopolio y la visibilidad del conocimiento euro-occidental, así como por la descalificación y la invisibilidad del saber campesino, este artículo se centra en los libros del Programa Nacional de Libros Didáticos (PNLD) del educación campo, prestando atención a los conocimientos y las formas de vida que se presentan y para cómo se presentan. A través de la selección y el análisis de los acontecimientos imagéticos y textuales, son discutidas las jerarquías del conocimiento y de formas de vida en el material en cuestión. El artículo resulta de una investigación sobre raza y género en el PNLD del educación campo, lanzado en 2013. Por el análisis de todos los libros del programa, la investigación revela dos eventos centrales en las formas en que la raza y el género performam estos libros: la colonialidad del saber y el estilo politicamente correcto.

PALABRAS CLAVE

colonialidad; políticamente correcto; libros didácticos; educación del campo. 
CAMPESINO: Un campesino no tiene ni casa, ni plata. Solamente sus hijos.

(Luis Alberto Ortiz, 8 años)

Pobre.

(Natalia Andrea Valencia, 8 años)

Los que se visten feo.

(Diego Alejandro Giraldo, 8 años)

Que son desplazados.

(Edwin Alexander Hoyos, 8 años)

Es una persona de la tierra.

(Julián David García, 11 años)

Es una persona inútil que no sabe nada.

(Jennifer Katia Gómez, 9 años $)^{1}$

Em definições do que é um campesino (camponês/a), vemos nas afirmações crianças de uma região rural da Colômbia nos dando a ver, com suas palavras, imagens francas e duras sobre seus mundos. Em uma dupla consciência que olha para si pelos olhos de um outro, as definições de campesino apontam para um distanciamento dessa identidade como própria, ora desvalorizando os modos de vida do campo, ora indicando o reconhecimento de uma subalternização. ${ }^{2}$ Tais descrições apontam tanto para os modos de espoliação dessas vidas como para uma espécie de esquecimento de si e dos próprios pertencimentos. À exceção de Julián David García (11 anos), que faz uma descrição positiva de campesino, entendendo-o como uma "pessoa da terra", o olhar das crianças apresenta campesino como uma identidade desvalorizada: alguém a quem falta casa e dinheiro, alguém que é pobre, alguém que se veste mal, alguém que migra forçosamente, ou alguém que não possui saber e é inútil. Uma identidade construída por faltas, ausências. Tal olhar indica uma agudeza descritiva dos modos de exploração e expropriação das populações do campo (não ter casa, a pobreza, a remoção ou migração forçosa), mas também aponta para uma ordem social que caracteriza como pobreza a ausência de modos de consumo euro-ocidentais, como ignorância, o pensamento não científico e não

1 Casa de las estrellas: el universo contado por los niños, dicionário que apresenta tais definições; foi publicado por Javier Naranjo em 1999 (Editora Aguilar). Ao longo de dez anos, Naranjo solicitou a suas alunas/os de escolas rurais do leste da Colômbia que definissem as palavras que compuseram esse dicionário.

2 Sobre a dupla consciência, Du Bois (1903) afirma: "It is a peculiar sensation, this double-consciousness, this sense of always looking at one's self through the eyes of the others, of measuring one's soul by the tape of a world that looks on in amused contempt and pity". [É uma sensação peculiar essa dupla consciência, esse senso de estar sempre olhando para si por meio dos olhos de outros, de medir a própria alma com a fita métrica de um mundo que (nos) olha com um entretido desprezo e pena]. 
ocidental, como inúteis as vidas que não se colocam nas lógicas de produtividade do mercado e do consumo.

Tais imagens/definições nos remetem a um tipo particular de violência simbólica que está mais ou menos espalhada por toda parte no Sul global. ${ }^{3}$ Os esquemas de percepção que sustentam essa violência estão fundados na colonialidade, que é a expressão de um padrão de poder que habitamos e que nos habita, como discute Quijano (Pereira Filho, 2008). O mundo moderno-colonial tem como marco "o encontro da civilização europeia com as civilizações que se inventaram deste lado do Atlântico" (Porto-Gonçalves, 2002, p. 3), em que relações assimétricas e exploratórias foram historicamente estabelecidas. A espoliação colonial foi legitimada por um conjunto de concepções que estabeleceu diferenças incomensuráveis entre o/a colonizador/a e o/a colonizado/a (Castro-Gómez, 2005). O racismo e a escravidão são centrais nesse novo sistema-mundo (Quijano, 2009; Santos, 2005; Porto-Gonçalves, 2006). A ideia de raça operou como um dispositivo taxonômico que estabeleceu o/a colonizado/a como uma diferença-menor, sobre a qual se justificava a violência e a exploração. Entretanto, a colonialidade vai além do colonialismo, pois é mais que uma imposição política, bélica ou administrativa, tendo sobrevivido à emancipação político-administrativa das colônias latino-americanas, asiáticas e africanas (Quijano, 2009). Como discutem Oliveira e Candau (2010), a colonialidade diz respeito a uma invasão-destruição do imaginário do outro e sua ocidentalização. "Opera-se, então, a naturalização do imaginário do invasor europeu, a subalternização epistêmica do outro não europeu e a própria negação e o esquecimento de processos históricos não europeus" (idem, p. 19). Escapar do espelho distorcido apresentado pela colonialidade (nas mídias, na escola, na ordem colonial capitalista, nas interpelações a se conformar aos moldes culturais hegemônicos) é um modo de resistir à destruição dos saberes e modos de vida das pessoas do campo.

Os movimentos do campo têm protagonizado lutas emancipatórias que buscam reescrever, a partir de um lugar subalterno, a história da moderno-colonialidade e de seus modos de hierarquização (Porto-Gonçalves, 2006). Considerando a descolonização do pensamento como uma luta fundamental, movimentos de educação do campo apresentam (e representam) outras matrizes de racionalidade subalternizadas, como as de pessoas negras, mulheres, não heterossexuais, amazônidas, nordestinas, caipiras e roceiras (Araújo, 2010), resistindo aos modos de expropriação da vida, e re-existindo saberes e modos de vida que foram subalternizados (Porto-Gonçalves, 2006).

A subalternização dos saberes do campo é ativamente produzida pela monocultura do saber euro-ocidental, sendo também uma forma de injustiça epistêmica. A dita ausência de saber do campesino ("aquele que não sabe", "inútil”) foi historicamente produzida por meio de desqualificação e invisibilização. O que

3 O Sul global é um sul sociológico e não geográfico, uma construção moderno-colonial que exprime várias formas de subalternização: expropriação, silenciamento, diferenciação, desigualdade (Santos; Meneses; Nunes, 2005). Do mesmo modo, falar em "Norte" também não se refere a uma posição geográfica, mas ao polo hegemônico da ordem colonial capitalista. 
o cânone euro-ocidental não legitima ou reconhece é tornado inexistente ou uma expressão de ignorância e incultura (Santos, 2002). Transformar a dita ausência de saber em presença, em conhecimento, é uma forma de resistência e re-existência epistêmica e cultural à colonialidade e aos seus modos de subalternização. É preciso reconhecer os direitos (inclusive os patrimoniais) sobre os conhecimentos que os povos do campo e indígenas mantiveram e elaboraram nas mais adversas condições nos últimos quinhentos anos (Porto-Gonçalves, 2002).

O discurso do desenvolvimento atualiza as formas de subalternidade produzidas pelas relações de poder coloniais (Barcellos, 2008), tratando como atrasado tudo o que difere de sua norma temporal geopolítica, supostamente avançada, dada como medida para o restante do mundo (Santos, 2002). Aliado às concepções de progresso, modernização, crescimento, produtividade, consumo, o desenvolvimento como norma hierarquiza povos e saberes. Os que estão fora dessa ordem são tratados como ultrapassados, improdutivos, subdesenvolvidos. $\mathrm{O}$ desenvolvimentismo é uma expressão da ordem euro-ocidental, que impõe suas prioridades culturais, com a pretensão de civilizar os outros povos, quando na realidade destrói e rouba sua humanidade, diversidade e identidade por meio da colonização dos recursos, da história, do passado e do futuro desses povos (Shiva, 2005).

As populações do campo constituem, em muitos casos, culturas de subsistência, o que difere radicalmente da pobreza inventada pelo desenvolvimento. ${ }^{4}$ $\mathrm{Na}$ ordem desenvolvimentista, euro-ocidental, as pessoas são consideradas pobres por comerem frutos das regiões onde vivem, em vez de alimentos processados e distribuídos pelo agronegócio; por construírem habitações com materiais naturais (pau a pique, adobe, palha), em vez de cimento; por vestirem roupas feitas com fibras naturais, tecidas localmente, em vez das roupas sintéticas do mercado global (Shiva; Mies, 1993). A educação do campo é um modo de recuperar e valorizar sistemas de produção sustentáveis, medicinas tradicionais e modos de vida e de relação com a terra que a ortodoxia produtivista capitalista, urbana e euro-ocidental invisibilizou e/ou descredibilizou.

Importante citar que este artigo é parte de uma pesquisa sobre gênero e raça nos livros didáticos de educação do campo. ${ }^{5}$ Ao longo da pesquisa, pude dar a ver pelo menos dois acontecimentos ordenadores dos modos em que raça e gênero performam nesses livros: a colonialidade do saber e o estilo politicamente correto. A colonialidade é ampla, pois se faz presente não apenas nos modos de enquadrar

4 As vidas camponesas podem estar marcadas pelas duas ordens (em que há, ao mesmo tempo, cultura de subsistência e pobreza como expropriação). Entretanto, é preciso diferenciar cultura de subsistência, a pobreza como expropriação e a pobreza inventada pela ordem desenvolvimentista. Tal distinção é necessária especialmente para que o discurso desenvolvimentista do capital não colonize os modos de vida não marcados pelo consumo de produtos industrializados e pela lógica consumista do mercado.

5 Foram analisados todos os livros aprovados pelo PNLD, do Ministério da Educação (MEC). Esse programa distribui gratuitamente livros a estudantes das escolas públicas do país. Em 2013 foi distribuído material aprovado no primeiro edital do MEC para a educação do campo (apenas duas coleções, em um total de 14 livros do $1^{\circ}$ ao $5^{\circ}$ ano do ensino fundamental). 
gênero e raça, mas no referencial euro-ocidental sobre o que é cultura e educação dos livros didáticos em questão. Já o estilo politicamente correto parece constituir uma resposta esvaziada às demandas de justiça epistêmica dos movimentos feministas, LGBT e antirracistas - e está mais restrito aos modos em que gênero e raça figuram nos livros. Os dois acontecimentos curriculares perpassam os livros de educação do campo (do Programa Nacional do Livro Didático - PNLD), com diferentes intensidades.

A colonialidade manifesta-se de diversas formas nesses livros, desde a manutenção da objetivação dos povos africanos escravizados no Brasil até os modos eurocentrados de fazer história e de eleger/selecionar o que é literatura. Pressupõe a universalidade da experiência euro-ocidental, em que a visão etnocêntrica e paroquial da história europeia torna-se referência da história, do tempo, da experiência humana (Dussel, 2005). A pluriversidade de saberes e experiências é guetizada (transformada em tradicional, folclórica ou pré-moderna) ou silenciada, e a especificidade histórico-cultural europeia é tomada como superior e padrão. A pretensão de superioridade dos saberes produzidos na Europa (e seus prolongamentos bem-sucedidos) é um aspecto importante da colonialidade do poder, assim como a paralela subalternização dos outros saberes, por meio da exclusão, omissão e guetização (Grosfroguel, 2009). A descolonização dos enunciados e visualidades é um movimento fundamental para um verdadeiro reconhecimento das diferenças. Descolonizar os discursos históricos, descolonizar as imagens racializantes (para além da alternativa politicamente correta), descolonizar as ideias de desenvolvimento, consumo, pobreza, descolonizar os mundos literários de referência. Esses são alguns desafios que se colocam, tomando-se como base os livros analisados, e que em larga medida não conseguem sair de um referencial colonial do conhecimento.

Paralelamente, o discurso politicamente correto dos livros - que apenas insere no campo visual pessoas brancas e não brancas, mas não problematiza os modos de produção do racismo - continua a perpetuar a ordem racista vigente. Do mesmo modo, as representações eventuais de homens lavando louças ou cozinhando não é suficiente para transformar uma sensibilidade sexista hegemônica na sociedade. Enfrentar racismo, sexismo e heterossexismo requer esforços na transformação da sensibilidade em discursos explícitos, tanto por meio da imagética como de textos. $\mathrm{O}$ enfrentamento do racismo, por exemplo, dos privilégios da branquitude, requer uma política propositiva, e não apenas a "correção colorida", politicamente correta, que é puramente emblemática e esvaziada de densidade transformadora.

\section{NOTA SOBRE OS LIVROS E SOBRE O MODO DE PESQUISAR}

O exercício da pesquisa consistiu em apontar para os modos de pensar-criar um currículo de educação do campo que os livros didáticos materializam. Note-se que a pesquisa não é entendida aqui como o reconhecimento de uma ordem curricular prévia, mas como uma experimentação em que se ensaiam relações, fazem-se composições, tecem-se geografias (Tadeu; Corazza; Zordan, 2004). As problematizações apresentadas não visam corrigir erros ou desmistificar, mas visibilizar forças em ação, assim como formular os problemas que essas forças colocam (idem). 
O que apresento neste artigo não é uma descrição ou cartografia das obras tarefa árdua dada a extrema heterogeneidade de cada livro -, mas uma tentativa de tornar visíveis alguns campos de regularidades, acontecimentos que se repetem em todo o conjunto. Busquei criar um campo de vidências apresentando dois acontecimentos centrais nos livros: a colonialidade e o estilo politicamente correto. As obras apresentam posicionamentos não unívocos sobre as hierarquias de raça, gênero e dos modos de exploração eurocên tricos (como as hierarquias de saberes e de habitações), assim como tentam resolver as demandas dos movimentos sociais (especialmente os antirracistas e de mulheres) pela estratégia esvaziada e puramente emblemática do politicamente correto. As análises elencadas para este artigo focam em retóricas e imagéticas problemáticas, que requerem reestruturação. Isso não significa que os livros se mantêm assim como um todo, mas os trechos analisados são exemplares de uma episteme não questionada. Imagens descolonizadoras aparecem de forma periférica e sem intensidade, por esse motivo não constam desta análise.

\section{ACONTECIMENTOS CURRICULARES}

\section{MODOS DE HABITAÇÃO E DESENVOLVIMENTO}

Os modos de habitação são um tema presente nos livros didáticos de educação do campo que remete indiretamente a modos de subalternização (como a desqualificação dos sujeitos que moram em certas habitações), assim como traz à tona tecnologias de construção não ocidentais para um campo de visibilidade positiva. Trazer aos livros didáticos as diversas formas de habitação dos povos do campo, e não apenas supor como moradia digna os modos de habitar euro-ocidentais, é um movimento importante de descolonização. O modo como um lugar é percebido e sentido, o modo como cada povo ou grupo é disposto e dispõe espacialmente suas habitações, o modo como se qualifica ou desqualifica os lugares, casas e os diferentes subespaços constituem tema de relevância para uma política descolonial (Porto-Gonçalves, 2006).

O tema é de fundamental importância para o questionamento da ordem colonial desenvolvimentista e sua particular visão sobre o que é riqueza e pobreza, tecnologia e não tecnologia, saber e ignorância etc. (Shiva; Mies, 1993). Por exemplo, a pobreza, na lógica colonial desenvolvimentista, está associada à ausência de padrões de consumo ocidentais e, portanto, à ausência de consumo de mercadorias produzidas e distribuídas pela economia de mercado. Nessa ordem, as culturas de subsistência sustentáveis são automaticamente reputadas como pobres, feias, primitivas, indignas, a quem o "desenvolvimento" ainda não chegou. Assim, casas de palha e abobe são consideradas piores que as casas de cimento e tijolo. A ideia de desenvolvimento é um modo de forçar os "não desenvolvidos" a se adaptarem aos modelos socioeconômicos e culturais do Ocidente (Santos; Meneses; Nunes, 2005), sendo, portanto, uma forma da colonialidade.

Um livro de alfabetização de $1^{\circ}$ ano apresenta alguns tipos de habitação feitos com diferentes técnicas de construção e materiais: palafitas, pau a pique, alvenaria, 
madeira, adobe, palha, cimento. ${ }^{6} \mathrm{~A}$ unidade é chamada "Jeitos de morar" e mostra diferentes tipos de habitação que vemos no país. As imagens são de habitações que em uma perspectiva colonial desenvolvimentista seriam tratadas como signo de pobreza - pois construídas por quem as habita, com materiais naturais em vez de materiais industrializados. A mera apresentação de vários "jeitos de morar" já problematiza a colonialidade dos modos de habitação na ordem visual. Dar a ver habitações outras, que não a casa de cimento-tijolo-telha, é um modo de iniciar uma descolonização do olhar. Entretanto, nos livros analisados, essas são casas de exceção, são casas dos capítulos sobre habitação. No restante de cada livro, a casa normativa, a casa de pano de fundo, a casa desenhada para se falar de outros temas é a casa de cimento-tijolo-telha, e é essa casa que de forma insidiosa acaba por performar a noção de casa dos livros. Ela é a casa "universal" naturalizada, que não é percebida como um particular (ocidental) modo de habitação, diante da qual as outras casas figuram como diferença subalterna.

Há um discurso explícito nos livros que aponta para a diversidade de modos de habitação, mas há também uma casa de pano de fundo, uma casa normativa. Essa é uma retórica comum nos discursos liberais politicamente corretos em educação (Oliveira, 2011), em que se faz uma defesa explícita de certas agendas, mas tal defesa não se sustenta nos demais discursos e imagens que não tratam explicitamente do tema. Como a retórica politicamente correta é um emblema esvaziado, os discursos e imagens dos livros escapam dessa ordem (politicamente correta) a todo tempo, e uma incongruência se instala na ordem discursivo-imagética. Um exemplo é que na mesma unidade "Jeitos de morar", apresentada antes, há outra ordem discursiva, não tão evidente, que apresenta as habitações valendo-se do paradigma colonial desenvolvimentista: encerrando a unidade, a história dos três porquinhos é narrada em texto e imagem.

Assim, a mesma unidade que se inicia apresentando diferentes tipos de habitação encerra com a história dos três porquinhos, em uma variação do conto britânico do final do século XIX. Em uma clara hierarquia, a história faz a direta associação entre tipos de habitação e avaliações de caráter moral sobre seus habitantes. O porco Cícero, que constrói sua casa com palhas, é descrito como "apressado"; Heitor, que constrói sua casa com tábuas (descritas como "gravetos"), é chamado de "preguiçoso"; e Prático, que constrói sua casa com "tijolos" e cimento, é chamado de "prevenido". A casa de tijolos e cimento é a única que resiste à destruição pelo lobo, indicando uma hierarquia das moradias fundada em concepções coloniais desenvolvimentistas. Notemos que a palha é um material amplamente usado nas moradias indígenas e quilombolas. A desvalorização do conhecimento e das tecnologias envolvidas na construção de casas de palha é evidente pela sua caracterização como "casa de apressado", assim como por sua fácil destruição pelo lobo. De forma semelhante, a imagem da casa de madeira pode remeter tanto a uma habitação

6 Especialmente na coleção Girassol - saberes e fazeres do campo (Carpaneda et al., 2012; Bonjorno et al., 2012), há uma clara preocupação em apresentar diferentes tipos de habitação e construir imagens menos hierarquizantes sobre elas. 
ribeirinha, quanto a uma casa das periferias urbanas do Brasil. A narrativa promove uma subalternização desse tipo de habitação ao caracterizá-la moralmente como casa de "preguiçoso", reiterando a desvalorização social desse tipo de habitação e culpabilizando moralmente quem faz e habita tal tipo de casa.

A desigualdade epistemológica que emerge do não reconhecimento de outros saberes e tecnologias de construção, como opera a história dos porquinhos, configura uma hierarquia epistêmica, em que se marginalizam e diminuem os saberes não ocidentais (Santos; Meneses; Nunes, 2005). A moralidade implicada nessa história nos aponta para como o colonialismo se mantém como colonialidade dos saberes e dos modos de vida (Quijano, 2009). Uma epistemologia crítica, em que o conhecimento é pensado como situado e as comparações entre conhecimentos são orientadas em virtude dos diferentes modos de intervenção que eles encarnam, traria outro olhar sobre os modos de habitação e os saberes e tecnologias envolvidos (Santos; Meneses; Nunes, 2005).

Ao contrário da moral dos três porquinhos, uma leitura alternativa sobre as casas de palha e madeira é que são sustentáveis, ou que são adaptadas ao clima e ao ambiente. Sua tecnologia seria avaliada pelos diferentes efeitos e consequências sobre o mundo, e não fundada em concepções de pobreza e atraso - que legitimam formas não sustentáveis de vida, por exemplo. Além disso, construir a própria habitação requer um complexo conjunto de vários saberes, que em geral não são os saberes euro-ocidentais da engenharia e da arquitetura. Na contramão do discurso inicial da unidade, que apresenta diferentes tipos de habitação (diferentes "jeitos de morar"), essa história aponta para o fato de que os discursos politicamente corretos do livro não se conseguem sustentar além de clichês da diversidade e de palavras de ordem.

\section{“ESCRAVAS” E “MUCAMAS”: GÊNERO E COLONIALIDADE}

Em um livro de história de $2^{\circ}$ ano (Editora Moderna, 2012, p. 343), vemos a família colonial performar como a "família do campo" de duzentos anos atrás. ${ }^{7} \mathrm{Da}$ diversidade de organizações "familiares" e modos de constituir espaços e relações de intimidade e ajuda mútua que existiam no Brasil do século XIX, apresenta-se no livro a família (euro)colonial, patriarcal e escravagista para se discutir a "nossa vida familiar", como indica o nome da unidade em que essa seção se situa.

A seção chama-se "Famílias de outros tempos" e é seguida pelo subtítulo "Famílias que viviam no campo", o qual tem um breve texto e uma imagem. A imagem apresenta imageticamente uma família branca e heteropatriarcal do século XIX, com duas jovens meninas negras apresentadas como "mucamas" (no texto, nas legendas e no glossário). $\mathrm{Na}$ foto, essas jovens meninas estão cada uma em um extremo, apontando imageticamente para seu pertencimento subalternizado e periférico à família. Além disso, uma delas está ajoelhada, em uma posição de serviço e subserviência. Tal imagética não é questionada ou problematizada no livro.

7 O trecho encontra-se na unidade 4 de um livro de história de $2^{\circ}$ ano (Editora Moderna, p. 343). A unidade é denominada "Nossa vida familiar", e o trecho em questão corresponde à terceira seção da unidade. 
As legendas da imagemo afirmam "família acompanhada de duas mucamas", e o glossário e o texto que acompanham a imagem descrevem "mucama" como "escravas que trabalhavam na residência de seus senhores" e que "cuidavam dos filhos dele e das tarefas domésticas".

Em primeiro lugar, é importante notar que falar em escravas é diferente de falar em pessoas escravizadas. A combinação da imagem e da legenda é problemática, pois associar negritude e escravidão emparelha de modo naturalizado raça (negra) e status civil (escrava) (Bernardino-Costa, 2007). Diversamente, falar em pessoa escravizada mostra o caráter contingente dessa associação - entre negritude e escravidão -, trabalho fundamental de historicização, e que não é feito no livro.

Além disso, chamar tais jovens meninas negras de "escravas" reitera o discurso colonial que não tratava essas vidas como humanas, mas sim como objetos de comércio e uso, coisas-escravas. Falar em "escravas" é continuar a tratar essas meninas-pessoas como objetos de comércio, "coisas", como discute Lélia Gonzalez (1983). ${ }^{8}$ Entretanto, trata-se de "pessoas negras", de "gente" - como afirma politicamente Gonzalez (idem) -, de jovens meninas de origem africana, escravizadas no Brasil e por essa família. O discurso objetivante do livro nega o estatuto de humanidade a essas jovens; elas são "escravas", objeto, coisa, mercadoria, e não pessoas escravizadas e exploradas. E isso é muito diferente. Não se trata de uma correção linguística politicamente correta, mas de um exercício de historicização que consiste em desnaturalizar, em perceber as práticas que instituem as posições e identidades. "Escrava" é o correlato de uma prática de escravização, portanto as palavras nos enganam quando nos fazem acreditar na existência de identidades prontas, em vez de nos fazer pensar nas práticas que as constituem (Veyne, 1998). Ou seja, em um olhar historicizante, as identidades existem apenas dentro de uma prática, o que nos permite compreender o processo de construção e subalternização das identidades do passado e atuais, em vez de tomá-las como naturais ou evidentes. ${ }^{9}$

Um tipo semelhante de problema acontece quando o texto afirma que "as famílias ricas tinham escravos que trabalhavam na fazenda". A objetivação "famílias ricas" também apaga o fato de que essas famílias enriqueceram à custa do trabalho escravo, da exploração do trabalho não branco. A riqueza, na construção discursiva da frase, aparece naturalizada, em vez de ser mostrada como um processo que envolveu expropriação, especialmente se pensarmos na produção da riqueza na ordem

8 Contudo, vale a pena ressaltar que as "coisas" só adquirem esse caráter de descartabilidade na ordem de uma economia de mercado capitalista. Essa desvalorização dos objetos e das coisas é, na realidade, uma referência à mercadoria, esta sim esvaziada de seu valor material, para funcionar apenas como signo abstrato, como valor de troca. Os objetos, em outros espaços (geo)políticos, são a própria materialidade da memória, da história, do desejo, que muitas vezes trabalham a existência de quem o usa, transformando-a (Stallybrass, 2004).

9 Não se trata de uma defesa do uso da expressão "pessoas escravizadas" em substituição à palavra "escrava". A palavra "escrava" pode ser usada desde que o texto aponte para as práticas de escravização e não tome a identidade como naturalizada e sem problematizá-la, como acontece nos livros didáticos em questão. 
colonial - no caso da família da imagem em questão, pode-se afirmar que a produção da riqueza envolveu expropriação, no mínimo, por meio do trabalho escravo. ${ }^{10}$

O livro, ao não problematizar o processo de escravização e repetir acriticamente as mesmas categorias coloniais - pensando o passado pelas categorias coloniais, identificado com essa posição, tratando a pessoa negra como escrava (coisa) -, faz a opressão histórica recair novamente sobre os ombros das populações subalternizadas, por meio de uma historicização que não reconhece a humanidade dessas pessoas, reforçando o racismo. Seria importante olhar para essas meninas negras - ou tantas outras pessoas negras escravizadas que são nos livros reduzidas apenas à condição de escravas - problematizando o processo de escravização, assim como olhar para além dessa relação, apontando outras histórias.

Na história da colonização das Américas, a escravidão começa a ser associada às pessoas negras (Bernardino-Costa, 2007). ${ }^{11}$ Essas colocações reiteram uma associação naturalizada entre trabalho doméstico e mulheres negras (escravizadas), reforçando o imaginário social racista e sexista. Quando as jovens meninas negras são tratadas como mucamas, a associação entre trabalho doméstico (um trabalho desvalorizado na ordem patriarcal racista) e negritude feminina se atualiza, reiterando a subalternização das mulheres negras. Não problematizar essa associação, ou reiterá-la como faz o livro, é fortalecer um processo de naturalização da subalternização das populações afrodescendentes, assim como da divisão racial e sexual do trabalho tal qual se apresenta hoje no Brasil - em vez de problematizá-la e apontar suas raízes históricas. Ensinar a pensar história nesse caso requereria apresentar o caráter contingente dessa associação (trabalho doméstico, mulher negra e escravidão), e não reduzir a mulher negra à condição de escrava doméstica, ou à sua relação com o senhor, ou com a "dona da casa", como faz o texto (idem).

A imagem das jovens meninas negras nos cantos da foto e sua descrição como mucamas são ressonâncias racistas e sexistas patriarcais da escravização de mulheres negras no Brasil. As imagens de meninas negras jovens referidas como "escravas"/"mucamas", responsáveis pelo trabalho doméstico em uma família branca, fazem reverberar na atualidade as dimensões históricas da escravidão no Brasil. Ainda hoje a maior parte da trabalhadoras domésticas do país é composta por mulheres negras (idem).

O trabalho doméstico ainda é identificado à escravidão e carrega o peso dessa história de opressão/subalternização. As identidades produzidas sobre a ideia de raça (identidades do colonialismo europeu) e de gênero foram associadas aos papéis

10 Note-se que críticas apresentadas ao trecho devem-se ao fato de que o livro não trata tais questões com mais profundidade, ou apresenta outras facetas. Os textos são curtos, e não há no livro textos mais específicos, nem problematização sobre tais questões.

11 No Brasil houve um intenso tráfico de pessoas africanas para o trabalho escravo. Até o ano de 1850, 4,8 milhões de pessoas africanas escravizadas entraram no Brasil - oito vezes mais que a população de Portugal que migrou para o Brasil até a mesma época (Castro, 2013). O Brasil é o país com mais afrodescendentes fora da África, tendo recebido $43 \%$ do total de pessoas africanas que foram arrancadas de seu continente de origem (idem). 
e funções que as mulheres negras ocupavam na estrutura de controle do trabalho que se formou no colonialismo. Raça, gênero e divisão do trabalho tornaram-se profundamente associados - e se mantém até hoje uma clara e sistemática divisão racial e sexual do trabalho. A não problematização dessa foto e o modo como os textos descrevem "as famílias que viviam no campo" mantêm um imaginário racista e sexista no qual as mulheres negras são as pessoas a quem cabem ("destinadas") os trabalhos domésticos.

O livro não historiciza os lugares sociais, reificando-os e tornando-os naturais pela comparação que a leitura pode fazer com as atuais configurações da divisão racial e sexual do trabalho, em que a maior parte das trabalhadoras domésticas é mulher e negra. Não problematizar essa imagem significa deixar intactas as estruturas de poder e privilégio - sexistas e racistas - instituídas no período da escravidão e as quais têm efeitos ainda hoje. ${ }^{12}$ Como discute Sueli Carneiro (2003), as mulheres negras tiveram uma experiência histórica diferenciada (das opressões das mulheres brancas), e é preciso reconhecer a diferença qualitativa que o efeito da opressão sofrida teve e ainda tem para as mulheres negras. Ainda segundo a mesma autora, a empregada doméstica é uma imagem paradigmática de um modo de opressão histórico e um elemento central de análise da condição de marginalização das mulheres negras na atualidade. "Ontem, a serviço de frágeis sinhazinhas e de senhores de engenho tarados. Hoje, empregadas domésticas de mulheres liberadas e dondocas [...]" (idem, p. 50).

Diversamente, como breve contraponto, cito o extrato de um texto da Articulação de Organizações de Mulheres Negras Brasileiras (2012, p. 15) que encadeia colonialismo, racismo, patriarcado e trabalho doméstico, o qual poderia inspirar esses livros historicizando a subalternização do trabalho doméstico:

[...] africanas escravizadas entraram neste país para trabalhar. Passados mais de 120 anos do fim formal da escravidão, milhões de mulheres negras permanecem realizando tarefas assemelhadas àquelas que realizavam no período em que viviam privadas de liberdade e, em sua maioria, estão descobertas de direitos trabalhistas e excluídas do sistema previdenciário.

\section{A DEMOCRACIA RACIAL}

$\mathrm{Na}$ mesma ordem discursiva do trecho do livro didático anterior, o texto “Os doces das sinhás" (Editora Moderna, p. 82, 4 ano) apresenta o mesmo uso da palavra escrava, mas agora com o termo "sinhá", reiterando, atualizando e naturalizando as posições "sinhá" e "escrava" em um livro de língua portuguesa. A imagem

12 Podemos nos lembrar de que, em agosto de 2013, uma jornalista brasileira branca afirmou publicamente que as médicas cubanas (negras) tinham cara de "empregada doméstica”. A jornalista levantava dúvidas sobre a possibilidade de mulheres negras serem mesmo médicas e não "empregadas", como supõe o imaginário racista das elites brancas brasileiras (Moura, 2013). 
de uma mulher branca com um bolo na mão ilustra o texto que afirma que "alguns doces costumavam ser feitos pelas sinhás e por suas escravas". Em um discurso aparentemente ingênuo, e não problematizado, vemos aqui se repetir em pano de fundo uma retórica imagética despolitizante do que significaram as relações de escravização. De maneira despretensiosa, reitera-se uma narrativa da nação que supõe que a escravidão no Brasil teria sido branda e benévola (Bernardino-Costa, 2007). A sinhá sorridente (uma imagem da boa senhora) carrega um doce feito por ela e por "suas escravas", em uma imagem da cordialidade dessas relações. Como discute Bernardino-Costa (idem), o mito da democracia racial está intimamente relacionado com o mito da boa senhora. ${ }^{13} \mathrm{~A}$ retórica da democracia racial supõe que havia intimidade, respeito e consideração entre senhoras e escravas e que não havia hostilidade racial (idem). Esse tipo de pano de fundo que povoa os textos pedagogiza (indiretamente) um olhar sobre as relações raciais no país.

No mesmo sentido, reiterando os discursos sobre a nação da democracia racial, vemos os textos e as imagens do título "Uma deliciosa mistura de sabores" em um livro de ciências (Bonjorno et al., 2012, p. 139, 40 ano) e de "Delícias de cada região" em um livro de língua portuguesa (Carpaneda et al, 2012, p. 79, $4^{\circ}$ ano).

Os dois textos falam da mistura de povos (indígenas, portugueses e "outros povos") que teriam formado a "cultura brasileira", e dessa "mistura" formou-se uma "culinária rica", com "delícias" e muitos "sabores". Ou, como sugere o título da primeira imagem e texto, trata-se de "uma deliciosa mistura de sabores"; uma celebração da mestiçagem por uma clara alusão aos discursos da nação como uma "deliciosa mistura de raças". A imagem estereotipada do indígena e do português sorrindo um para o outro também afirma a retórica da nação como harmoniosa mistura de povos/raças. As misturas de ingredientes e sabores é um paralelo com os discursos da nação miscigenada, da mistura interracial que teria harmonizado as diferenças e suavizado os conflitos - decorrentes da invasão, da pirataria, da escravização e das diversas formas de exploração colonial. Nesse discurso se faz presente a ideia de que a "mistura" (de "portugueses e muitos outros povos", assim como de alimentos e diversas tradições culturais) forma "delícias", uma "culinária rica". Os sabores deliciosos formados pela mistura de povos reiteram a imagem da nação miscigenada, na qual os conflitos e as hierarquias raciais são diluídos por essa "mistura", afirmando uma ordem social harmoniosa e consequentemente não racista ou patriarcal, em uma invisibilização das hierarquias e exclusões.

\section{MODOS DE FAZER HISTÓRIA: A EUROPA COMO CENTRO}

Nos livros, é corrente o referencial eurocêntrico orientando a narrativa historiográfica. No trecho de um livro de história de $5^{\circ}$ ano (Carnapeda et al., 2012, p. 1), vemos eufemismos eurocêntricos na narrativa que constrói a história da

13 É importante notar que a retórica da democracia racial não consegue explicar a racialização das condições de vida, dos níveis de pobreza, de escolaridade, de acesso às universidades, de moradia, de integração urbana, de acesso à riqueza que os diversos métodos estatísticos têm mostrado sobre a realidade nacional (Bernardino-Costa, 2007). 
invasão colonial. Tratar a invasão imperialista europeia pelo eufemismo "expansão territorial", assim como afirmar que os "séculos XV e XVI são considerados pelos historiadores [sic] como a época das grandes navegações", torna visível o referencial eurocêntrico dessa historiografia. A experiência particular e paroquial europeia é convertida no ponto central de referência de dois séculos, reduzindo a totalidade do tempo e do espaço da experiência humana a um ponto de vista particular, que se apresenta como referência universalizante (Lander, 2005). Trata-se de uma narrativa que situa a Europa no centro dos processos históricos. Classificar os séculos com base na narrativa do imperialismo europeu é um dispositivo colonizador do conhecimento, que estabelece a referência do conhecimento que importa. As outras histórias são transformadas em acessórias, diferentes, tradicionais que, no imaginário do progresso, é uma marca da sua inferioridade (idem). A Europa e seus "protagonismos" aparecem como local pelo qual as histórias do Sul global são contadas, fazendo da Europa o referencial da história (Araújo, 2010). Entretanto, como discute Chakrabarty (2000), é fundamental fazer uma história desde e para a periferia, provincializando a Europa e desenvolvendo uma narrativa que atente para as massas subalternizadas como agentes de mudança.

O caráter colonial dessa historiografia está também em seus eufemismos, como na afirmação sobre a "conquista de territórios estrangeiros" (diga-se invasão, genocídio e pirataria), assim como na valorização da tecnologia e da empreitada colonial quando fala que portugueses, ingleses, espanhóis e franceses lançaram-se "desbravando oceanos e mares". Note-se que a narrativa trata europeus como sujeitos que irão abrir caminhos, e os mares e oceanos ("natureza") como algo a ser desbravado pelos europeus. Trata-se da perspectiva da modernidade colonial em que a natureza, assim como as colônias, é considerada como algo que deve ser dominado, onde estão os povos que serão tratados como "povos em estado de natureza", "selvagens", e as terras e mares que serão desbravados. Nessa ordem eurocêntrica, moderno-colonial, o polo ativo é o moderno, que se "expande" para outras regiões, e a natureza, assim como os povos, lugares e regiões foram tratados como o lado passivo dessa história (Porto-Gonçalves, 2002). Essa retórica sobre "conquista" e "desbravamento" situa-se em um ponto de vista colonial, em que "descobrir", "conquistar" e "desbravar" coloca-se como um ato moralmente legitimado pela superioridade da civilização europeia, assim como pelas cartas de privilégio papais que transformaram pirataria em vontade divina, em direito natural do colonizador (Shiva, 2001). ${ }^{14}$

Em um livro de história de $4^{\circ}$ ano (Editora Moderna, 2012, p. 317), uma caravela portuguesa aparece como ilustração da disciplina. Trata-se da página de abertura em que essa é a única imagem que aparece ao lado da palavra "história". Essa imagética parece já indicar uma metonímia da noção de história do livro, uma confirmação do referencial eurocêntrico que se irá desdobrar. O livro segue em

14 Note-se que a atenção a essas narrativas, às expressões escolhidas para fazer a historiografia, ganha maior importância dada a completa ausência de problematização do que significa a empreitada colonial nos livros analisados. Tais termos poderiam não ser tão problemáticos se estivessem inseridos em um espaço de discussão e problematização da empresa colonial. 
uma narrativa eurocentrada, com algumas incursões que pretendem apresentar histórias indígenas e africanas. ${ }^{15}$

Entretanto, a historiografia segue um cânone eurocêntrico não problematizado. Mesmo quando apresenta outros povos, a narrativa ora os situa em uma lógica eurocolonial, ora como grupos homogêneos da diferença, ora despolitizando as histórias de expropriação e genocídio. A primeira unidade, intitulada "A aventura de navegar" (p. 318-325), assim como alguns dos seus subtítulos - como "Viagens espanholas" e "Viagens portuguesas"-, trata de forma amena e simpática (como "aventuras", "viagens") a empresa colonial que envolveu despossessão indígena, escravidão transatlântica etc. O "Tratado de Tordesilhas", por exemplo, é apresentado apenas como um acordo de distribuição do território. Entretanto, não se questiona que aquele território já era habitado por outros povos, assim como não mostra a arbitrariedade das cartas papais de privilégios que estabeleciam como direito natural a invasão europeia ("conquista"), assim como a subsequente pirataria e escravização (Shiva, 2001).

As terras que foram divididas entre Portugal e Espanha não pertenciam ao papa, entretanto elas foram por ele distribuídas entre os Estados em questão. Isso não é claro na narrativa do livro, ou de qualquer outro das coleções aprovadas. Ou seja, a politização historiográfica do que significa a propriedade no Brasil não é feita. O modo como a história é narrada não permite que se entenda que a propriedade no Brasil é uma criação eurocên trica dada por meio da invasão colonial, da pirataria da riqueza dos povos nativos e da expropriação que constitui o trabalho escravo.

O referencial eurocentrado também é evidente quando, em outro livro (Editora Moderna, 2012, p. 308, 5० ano), afirma-se que as capitanias hereditárias não funcionaram, pois "havia inexperiência, falta de recursos e, em muitas ocasiões, era necessário enfrentar ataques indígenas". O lugar de fala assumido pela narrativa corresponde à posição do colonizador, a quem eram endereçados os "ataques indígenas". Tanto o uso da palavra "ataque" (os colonos eram "atacados") como da categoria "indígenas" (denominação dada pelos colonizadores aos habitantes das terras invadidas) indicam o lugar de fala eurocentrado. Se o referencial da narrativa historiográfica fosse outro, mesmo que em tom generalizante, poderia falar-se em "resistência indígena", e não em "ataque". Note-se mais uma vez que não se trata

15 A primeira unidade (Editora Moderna, $4^{\circ}$ ano), intitulada "A aventura de navegar" (p. 318-325), apresenta os seguintes subtítulos: "Produtos valiosos", "Navegar em busca de riquezas", "Viagens espanholas", "Viagens portuguesas". A unidade 2 (p. 326-331) intitula-se "Os povos indígenas do Brasil", com os subtítulos: "Os antigos povos indígenas", "Portugueses e indígenas: os primeiros contatos", "O modo de vida dos indígenas". $\mathrm{Na}$ unidade 3 (p. 332-337), "Os povos que vieram da África”, apresentam-se os subtítulos: "Diferentes povos no continente africano", "Arte e cultura", "Ação dos europeus na África". A unidade 4 intitula-se "O início da colonização portuguesa na América", e a unidade 5, "A ocupação do território" - última parte do livro de história -, que retornam ao cânone eurocêntrico da historiografia. Entretanto, note-se que as unidades sobre os povos indígenas e africanos não conseguem apresentar um horizonte fora da ordem politicamente correta, que reduz as histórias desses povos a clichês da diferença, como reduzir o conhecimento e a história desses povos a "mitos e lendas" (p. 334). 
de corrigir palavras ou expressões. A retórica politicamente correta, como discutida anteriormente, ilustra como a correção vocabular e imagética, sem uma real alteração da episteme que orienta o pensamento, opera um achatamento e esvaziamento dos debates. Portanto não se trata de corrigir expressões "infelizes", mas de rever a episteme que orienta os modos de pensar e ensinar.

\section{A NATURALIZAÇÃO DA ESCRAVIDÃO DE PESSOAS NEGRAS}

Em um livro de história (Editora Moderna, 2012, p. 354, $3^{\circ}$ ano), solicita-se que se observe a imagem para responder à questão. A imagem apresenta uma aquarela de 1822, do pintor francês Jean-Baptiste Debret. Na imagem, dois homens negros descalços (um signo de que a pessoa era escravizada) carregam um homem branco em uma rede. Há também duas crianças negras descalças: uma carrega um guarda-chuva e a outra, frutas. No livro, a pergunta feita sobre a pintura é: "Qual meio de transporte foi representado na imagem?". "Trata-se uma imagem forte da escravidão colonial que é reduzida no livro a um "meio de transporte" de época, a uma peculiaridade histórica.

Tal modo de enquadrar essa imagem da escravidão deixa de apresentar a exploração humana que foi a escravidão no Brasil, assim como suas formas de desmoralização e de subalternização. A violência colonial exprime-se nessa imagem como uma dominação exercida sobre os corpos negros, sobre os espaços, sobre o movimento, sobre quem pisa na terra e quem não quer se sujar em sua "poeira"17. Os corpos fortes dos homens negros e o corpo delicado do homem branco expressam a relação deles com o trabalho. $\mathrm{O}$ corpo magro e delicado do homem branco é um corpo não marcado pelo trabalho, assim como o fato de ser carregado por fortes homens negros escravizados é também uma confirmação de que ele podia ter outras pessoas para trabalhar por ele, que podia comprar escravos e dispor de seu trabalho. Além disso, exibir-se sendo carregado por pessoas escravizadas conferia prestígio aos proprietários, um ícone de poder. Eximindo-se até mesmo do trabalho de caminhar, a imagem mostra uma forma de distinção social em que o homem branco se diferencia, em sua delicadeza, de qualquer marca de trabalho manual. Tratar essa imagem como uma questão que diz respeito a "meios de transporte" de época naturaliza a violência exercida sobre a população afrodescendente e não explora como os modos de vida racista-escravocratas do período colonial (como o da imagem em questão) podem ainda se manter vivos no imaginário social.

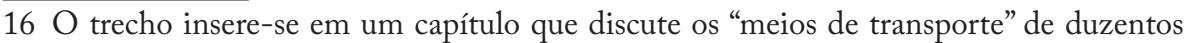
anos atrás.

17 As elites coloniais tinham uma percepção rebaixada do trabalho manual-corporal, que era ao mesmo tempo um modo de desqualificação dos que faziam esses trabalhos (pessoas negras escravizadas). No Brasil, o trabalho manual é até hoje desvalorizado (associação racista entre escravidão e negritude). A imagem do homem branco sendo carregado pelos homens negros escravizados é paradigmática da exploração dos corpos negros, em que nem mesmo caminhar é um trabalho corporal necessário para o branco, que prefere ser carregado. 


\section{"RESPEITO À DIFERENÇA": O OLHAR LIBERAL-INDIVIDUALISTA E O ESTILO POLITICAMENTE CORRETO}

Em um livro de matemática (Editora Moderna, 2012, p. 222, 4 ano), há um texto sobre o Dia da Consciência Negra intitulado "A matemática me ensina a ser uma pessoa que valoriza e respeita a cultura afro-brasileira". O título indica o modo de tratar as subalternizações raciais que se fazem presentes não apenas nesse livro, mas em todo o conjunto analisado: o referencial individualizante em que as discriminações são tratadas como uma questão de falta de respeito e/ou valorização individual. O discurso do "respeito às diferenças", "todos somos diferentes" e do "preconceito racial" tem um mesmo lastro: um pressuposto liberal-individualista sobre as hierarquias e subalternizações.

O texto afirma que "os negros [sic] começaram a ser trazidos da África por volta de 1550 " e que, por "350 anos, a maior parte do trabalho no Brasil foi realizada por escravos africanos". Em primeiro lugar, é um eufemismo afirmar que as pessoas negras começaram a ser trazidas da África. Na realidade, elas começaram a ser comercializadas e escravizadas de forma violenta e objetificada, diferente dos modos de escravidão que já aconteciam na África antes da presença europeia (Carvalho, 2010). Não se trata de "trazer" alguém, mas da migração forçada de milhares de pessoas para escravização. Além disso, não são "escravos africanos" que construíram o país, mas pessoas africanas escravizadas na ordem colonial. Esse trecho segue a ordem objetificante, em que as pessoas negras escravizadas são tratadas como "escravas" (coisas), e não como pessoas. O tom do texto é distante de uma noção politizada do que foi a escravidão no país, com seus castigos corporais, intervenções armadas, táticas de cooptação por pequenos privilégios (Sodré, 2005), assim como dos efeitos da escravidão sentidos até hoje pelas populações afrodescendentes.

No segundo parágrafo, afirma-se que "os escravos africanos", "além de sustentar a economia, [...] ajudaram a enriquecer nossa cultura". Podemos nos perguntar por que o texto não chama a economia de "nossa" - apenas a "cultura" é tradada como "nossa". O que o texto faz quando afirma que "escravos africanos [...] sustentaram a economia"? Que economia abstrata "os escravos africanos" "sustentaram"? Caberia perguntar: O trabalho escravo sustentou a economia de quem? $\mathrm{O}$ texto não torna visível a exploração, expropriação e acumulação de riqueza pela colonização europeia via escravização ao falar em termos abstratos e amenos sobre uma "economia" desencarnada que foi "sustentada" pelo trabalho de africanas e afrodescendentes escravizadas. Essa retórica dilui possíveis críticas contra os históricos e atuais privilégios da branquitude no país, assim como é desmobilizadora, evitando a formação de uma consciência política que poderia demandar reparação e justiça redistributiva, por exemplo.

O texto segue em um discurso que responsabiliza a pessoa subalterna por sua subalternização. Afirma que "com tantas contribuições para a cultura do país, os negros [sic] passaram a valorizar mais sua identidade", supondo que as pessoas negras estariam descontentes com sua identidade, com suas tradições culturais, com seu fenótipo, e em algum momento passaram a "se valorizar". Há uma completa omissão do lugar branco-colonial na desvalorização social das pessoas negras e dos 
legados afro-brasileiros, assim como das políticas de estado eugênicas e de branqueamento. No texto há uma clara evitação em focalizar o racismo, e também não mostra como a branquitude (um legado eurocolonial) constitui uma forte dimensão do privilégio racializado branco, em que as pessoas negras (ou mestiças mais escuras) estão em posição de subalternidade histórica. Ironicamente, a propósito do Dia da Consciência Negra, o texto parece esquecer-se de todas as ideologias racistas que constituíram a nação, das perseguições e coibições às diversas formas de organização da população africana e afrodescendente.

Esses discursos sobre o trabalho escravo e a "(des)valorização" da cultura afro pelas próprias afrodescendentes são seguidos de informações superficiais sobre Zumbi e o Quilombo dos Palmares, o qual é chamado de "forte e duradoura comunidade de escravos fugidos da América", reiterando o sentido escravo-coisa. O olhar que trata os quilombos como "comunidade de escravos fugidos"é o mesmo olhar colonial que vê "escravos", e não pessoas africanas, ou afrodescendentes. De forma alternativa, o texto poderia referir-se às comunidades de pessoas africanas que resistiram à escravidão, atentando para as formas políticas e culturais de resistência. A história das populações afro no Brasil fica invisibilizada em uma retórica sobre a nação que nega as formas de resistência afro à escravidão e à violência colonial. Esse tipo de narrativa não permite que se compreenda que as desigualdades raciais dos dias de hoje são fruto de uma história colonial e da escravidão. $\mathrm{O}$ texto a propósito do Dia da Consciência Negra acaba por ser um texto que trata as populações afrodescendentes de forma subalternizada.

O discurso politicamente correto se faz presente também pela retórica da diversidade. Em um livro de geografia (Editora Moderna, p. 364, $2^{\circ}$ ano), o título do capítulo, "Pessoas diferentes, jeitos diferentes", indica a lógica liberal-individualista em que o discurso sobre as alteridades se situa. Sem nenhuma problematização sobre a construção da diferença e da norma, o recorte essencializa e cristaliza a alteridade, em um "multiculturalismo reacionário"(Santos; Meneses; Nunes, 2005). O texto "Respeitando cada um" afirma que "mesmo diferentes [...] somos todos humanos" (Editora Moderna, p. 64, $2^{\circ}$ ano). ${ }^{18}$ A pergunta inicial a essa afirmação é: "Diferentes de quem?". Quem é a referência não nomeada pela qual a diferença se constitui? Qual é a norma que faz essas crianças "diferentes"? A diferença não é um dado a priori, mas algo que se constitui em relação, é uma atribuição feita a partir de uma determinada posição (Louro, 2002). A diferença é constitutiva da identidade normativa e, portanto, remete à norma que a constitui como diferença

18 O livro da coleção Girassol do $1^{\circ}$ ano (Carpaneda et al., 2012), em sua primeira unidade, tem como título "Quem sou eu" e o subtítulo é "Cada criança tem seu jeito de ser”. Além da grande semelhança dos títulos e retórica, as imagens também seguem o mesmo estilo, mostrando crianças inuítes, muçulmanas, indígenas etc. $\mathrm{O}$ discurso do "respeito às diferenças" também aparece em outros livros (no Projeto Buriti Multidisciplinar, $5^{\circ}$ ano, p. 300: "respeito é bom e todo mundo gosta"; $3^{\circ}$ ano, p. 318: "ser solidário" e "aprender a respeitar"; $2^{\circ}$ ano, p. 260, 262, 362: "somos diferentes"; e também na coleção Girassol, $4^{\circ}$ ano, p. 126 e 127: "orgulho de ser do campo"). 
subalterna. A ideia de "respeito" para com "o diferente" subestima as relações de poder que posicionam os sujeitos (idem).

As descrições das imagens, tais como "criança aborígene" ou "criança nepalesa", apontam para uma imprecisão geral da discussão, para uma planificação da diferença. Por exemplo, o uso da categoria colonial "aborígene" para descrever a diversidade de povos que foram assim nomeados pelo colonialismo inglês indica o lugar de fala pelo qual a "diferença" está sendo construída. Trata-se da construção da diferença como um grupo homogêneo a partir do olhar-referência colonial. A diversidade de povos e modos de vida é reduzida ao étnico, reafirmando a superioridade da norma, do padrão, da referência.

A diferença apresentada nas imagens é não branca. ${ }^{19}$ As imagens de crianças não brancas de diferentes povos e nacionalidades indica que elas, não brancas, são as “diferentes" e que devem ser "respeitadas". Entretanto o discurso do "respeito à diferença" não aponta para nenhuma estratégia pela qual essas diferenças se tornariam respeitáveis. Falar que alguém deve ser respeitado porque é diferente não empodera os grupos subalternizados, nem os mostra em seu valor - como são socialmente desvalorados, é importante mostrar seu valor. A retórica do "somos diferentes" não apresenta as pessoas, já supostamente subalternizadas, como dignas de respeito. Dar a ver a respeitabilidade desses povos requer mostrá-los em sua dignidade, valorizar seus modos de vida, conhecimentos, história, e não repetir a subalternização pelo pedido condescendente de "respeito".

Diversamente, uma estratégia descolonial envolveria valorizar a memória, saberes e identidade de grupos ou povos subalternos, mas não como vítimas, nem por uma gentileza politicamente correta, como ocorre em diversos livros analisados. Descolonizar os livros didáticos, apresentando a diferença de modo emancipatório, requer dar verdadeiro espaço aos conhecimentos dos povos conquistados (os conhecimentos dos diversos povos indígenas, das comunidades quilombolas, dos povos do campo), que têm sido reduzidos a mitos, irracionalidade, folclore, artefatos de museu, ou saberes práticos, e que ficam na dependência da ciência como comprovadora de sua legitimidade (Santos; Meneses; Nunes, 2005). Faz-se necessária uma reorganização da geopolítica do conhecimento, em uma interseção dos saberes ocidentais, e dos saberes suprimidos pelo euro-ocidentalismo (Mignolo, 2008). Nos livros em questão, os conhecimentos não científicos e não ocidentais são reduzidos a uma posição subalterna de saberes "alternativos", "diferentes", o que os enfraquece epistemologicamente (Santos; Meneses; Nunes, 2005).

Esse discurso da diversidade e do "respeito à diferença" reelabora formas de subalternização, reproduzindo relações de poder eurocoloniais (racistas, desenvolvimentistas) e reforçando o lugar de inferioridade da "diferença".

19 A norma não nomeada no livro, que constrói aquelas crianças como "diferentes", parece ser racializante e eurocolonial, ou seja, caucasiana, urbana, heteronormativa e demostra o consumo de roupas e modo de vida dos países industrializados. Esse é normalmente o sujeito "abstrato" e "universal" a quem a diferença parece contrapor-se. 


\section{RETOMANDO AS IMAGENS CURRICULARES}

O exercício da pesquisa que este artigo dá a ler consistiu em buscar entender as imagens curriculares que os livros didáticos do PNLD de educação no campo instituem e apontar como saber e poder se articulam. Nos livros, a ordenação das imagens, dos textos, das formas de perguntar, assim como a seleção do que faz parte da paisagem do possível/visível, indicou posições (geo)(sexo)políticas sobre o que deve ser conhecido. Ainda que seja difícil falar em retóricas e imagéticas hegemônicas nos livros, a colonialidade, o racismo, o sexismo se fazem presentes. A colonialidade faz parte do horizonte epistêmico dos livros em questão, nos modos de enquadrar gênero e raça, mas também de forma mais ampla, abarcando outros discursos.

A colonialidade se faz presente tanto nas formas que foram analisadas (nos modos de habitação, de fazer história, de narrar a nação, de naturalizar a escravidão de pessoas africanas), mas também aparece nos livros de outras maneiras, como nos horizontes literários eurocentrados, na referência constante a fadas, castelos, rainhas e reis brancas/os do mundo europeu, nas distinções modernas entre arte e artesanato, ou entre folclore e literatura, assim como outras não analisadas neste artigo. Já a estratégia politicamente correta enfraquece a possibilidade de críticas mais imediatas aos livros, pois a eventual inserção do discurso sobre o "respeito às diferenças" ou a "imagética colorida" dão a falsa impressão de resposta às demandas por justiça epistêmica. Entretanto, como já discutido aqui, a estratégia politicamente correta é esvaziada de densidade transformadora. Em primeiro lugar, porque é uma estratégia que não problematiza as discriminações e hierarquizações. Em segundo lugar, porque mantém a norma como referência, como padrão. E, por último, porque é um discurso de exceção, em um horizonte que não trata de forma clara e sistemática os modos de subalternização.

\section{“ES UNA PERSONA DE LA TIERRA”}

Uma das definições de campesino o afirma como "uma pessoa da terra", demarcando essa identidade por um pertencimento fundante, por uma igualdade compartilhada: dividimos a terra, nossa casa, com milhões de outras espécies. ${ }^{20} \mathrm{~A}$ definição está em consonância com as políticas de descolonização, em que a terra não é vista como propriedade privada, mas como fonte de vida e de existência. Nesse sentido, essa definição de campesino é uma afirmação política sobre justiça e sustentabilidade. Descolonizar o livro didático de educação do campo implica uma mudança em suas imagens e retóricas euro-ocidentais que possa dar a ver os modos diversos de subalternização (em sua geo-sexo-política) e os saberes que têm sido silenciados, caracterizados por outras formas de relacionar-se com a terra e de habitar o planeta.

20 Nessa frase, fiz uma pequena adaptação (e tradução) da afirmação de Vandana Shiva (2005, p. 62) para o meu argumento. A afirmação original é: "We share this planet, our home, with millions of species". A substituição foi de "planet" por Terra/terra. 


\section{REFERÊNCIAS}

Araújo, S. M. S. Educação do campo no Brasil: um discurso para além do pós-colonial? Revista Latinoamericana de Ciências Sociais Niñez y Juventude, Manizales, Colombia: Universidad de Manizales, v. 8, n. 1, p. 221-242, jan./jun. 2010. Disponível em: <http:// www.scielo.org.co/scielo.php?script=sci_arttext\&pid=S1692-715X2010000100011\&l

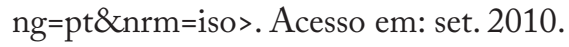

Articulação de Organizações de Mulheres Negras Brasileiras. Mulheres negras e o trabalho doméstico no Brasil. Cadernos InformAção AMNB, Porto Alegre, v. 1, 2012.

Barcellos, G. H. Desterritorialização e r-existência Tupiniquim: mulheres indígenas e o complexo agroindustrial da Aracruz Celulose. 2008. 373f. Tese (Doutorado) Universidade Federal de Minas Gerais, Belo Horizonte, 2008.

Bernardino-Costa, J. Sindicatos das Trabalhadoras Domésticas no Brasil: teorias da descolonização e saberes subalternos. 2007. 274p. Tese (Doutorado em Sociologia) Universidade de Brasília, Brasília, 2007.

Bonjorno, J. R. et al. Girassol-saberes e fazeres do campo: alfabetização matemática \& ciências. São Paulo: FTD, 2012. 4v. (2 a $5^{\circ}$ ano).

CARneiro, S. Enegrecer o feminismo: a situação da mulher negra na América Latina a partir de uma perspectiva de gênero. In: Ashoka Empreendimentos Sociais; Takano Cidadania (Orgs.). Racismos contemporâneos. Rio de Janeiro: Takano Editora, 2003. p. 49-58.

Carpaneda, I. et al. Girassol - saberes e fazeres do campo: letramento e alfabetização \& alfabetização matemática. São Paulo: FTD, 2012. (1 ano).

.et al. Girassol - saberes e fazeres do campo: letramento e alfabetização \& geografia e história. São Paulo: FTD, 2012. 4v. (2 a $5^{\circ}$ ano).

Carvalho, F. M. Diáspora africana: travessia atlântica e identidades recriadas nos espaços coloniais. Mneme - Revista de Humanidades, Rio Grande do Norte: Universidade Federal do Rio Grande do Norte; Centro de Ensino Superior do Seridó, v. 11, n. 27, p. 14-24, 2010. Disponível em: <http://www.periodicos.ufrn.br/ojs/index.php/mneme>. Acesso em: dez 2010.

Castro, M. "Brasil é um país de colonização mais africana do que europeia", diz historiador Luis Felipe Alencastro. Opera Mundi, 4 set. 2013. Notícias História. Disponível em: <http://operamundi.uol.com.br/conteudo/noticias/31026/brasil+e+um+ pais+de+colonizacao+mais+africana+do+que+europeia+diz+historiador+.shtml $>$. Acesso em: set. 2013.

Castro-Gómez, S. Ciências sociais, violência epistêmica e o problema da "invenção do outro". In: LANDER, E. (Org). A colonialidade do saber: eurocentrismo e ciências sociais. Perspectivas latino-americanas. Buenos Aires: CLACSO, 2005. p. 80-87.

Chakrabarty, D. Provincializing Europe: postcolonial thought and historical difference. Princeton: Princeton UP, 2000. 
Du Bors, W. E. B. The souls of black folk. Atlanta, GA: Gutenberg Ebook, 1903. Disponível em: <http://www.gutenberg.org/ebooks/408>. Acesso em: 4 out. 2016.

Dussel, E. Europa, modernidade e eurocentrismo. In: LANDER, E.(Org.). A colonialidade do saber. Eurocentrismo e ciências sociais. Perspectivas latino-americanas. Buenos Aires: CLACSO, 2005. p. 24-32.

Editora Moderna. Projeto Buriti Multidisciplinar. São Paulo: Moderna, 2012. 5v. (Obra coletiva concebida, desenvolvida e produzida pela Editora Moderna. Editora responsável: Marisa Martins Sanchez).

Gonzalez, L. Racismo e sexismo na cultura brasileira. Revista Ciências Sociais Hoje, Brasília: ANPOCS, v. 2, p. 223-244, 1983.

Grosfroguel, R. Para descolonizar os estudos de economia política e os estudos pós-coloniais. In: Santos, B. S.; Meneses, M. P. G. (Orgs.). Epistemologias do Sul. Coimbra: Edições Almedina, 2009. p. 383-418.

LANDER, E. Ciências sociais: saberes coloniais e eurocêntricos. In: (Org.). $A$ colonialidade do saber. Eurocentrismo e ciências sociais. Perspectivas latino-americanas. Buenos Aires: CLACSO, 2005. p. 8-23.

Louro, G. L. Currículo, gênero e sexualidade: refletindo sobre o "normal", o "diferente" e o "excêntrico". Labrys: Revista de Estudos Feministas, Florianópolis: UFSC, v. 1, n. 1/2, jul./dez. 2002. Disponível em: <http://www.labrys.net.br/labrys1_2/guacira1.html>. Acesso em: ago. 2016.

Mignolo, W. Desobediência epistêmica: a opção descolonial e o significado de identidade em política. Cadernos de Letras da UFF, Niterói: EFF, n. 34, p. 287-324, 2008. Dossiê: Literatura, língua e identidade.

Moura, R. Jornalista diz que médicas cubanas têm "cara de empregada doméstica". Folha de São Paulo, São Paulo, 27 ago. 2013. Cotidiano. Disponível em: <http://www1. folha.uol.com.br/cotidiano/2013/08/1332962-jornalista-diz-que-medicas-cubanastem-cara-de-empregada-domestica.shtml>. Acesso em: ago. 2013.

Oliveira, L. F.; Candau, V. M. F. Pedagogia decolonial e educação antirracista e intercultural no Brasil. Educação em Revista, Belo Horizonte: UFMG, v. 26, n. 1, p. $15-40$, abr. 2010.

Oliveira, R. M. Gênero e sexualidade na TVEscola: cartografias de um currículo. 2011. 278f. Tese (Doutorado em História) - Universidade de Brasília, Brasília, 2011.

Pereira Filho,J. Entrevista com o sociólogo peruano Anibal Quijano. Santiago, 11 de julio de 2006. Brasil de Fato, [S.1.: S.n.], 2008. Disponível em: <http://historiaemprojetos. blogspot.com/2008/10/entrevista-com-o-socilogo-peruano-anbal.html>. Acesso em: mar. 2013.

Porto-Gonçalves, C. W. O latifúndio genético e a r-existência indígeno-campesina. GEOgraphia, Rio de Janeiro: UFF, ano IV, n. 8, p. 39-60, 2002.

. Reinvenção dos territórios: a experiência latino-americana e caribenha. In: Ceceña, A. E. (Org.). Los desafíos de las emancipaciones en un contexto militarizado. Buenos Aires: CLACSO, 2006. p. 151-197. Disponível em: <http://bibliotecavirtual. 
clacso.org.ar/ar/libros/grupos/cece/Carlos\%20Walter\%20Porto-Goncalves.pdf>. Acesso em: mar. 2013.

Quijano, A. Colonialidade do poder e classificação social. In: Santos, B. S.; Meneses, M. P. G. (Orgs.). Epistemologias do Sul. Coimbra: Edições Almedina, 2009. p. 73-118. SAntos, B. S. Por uma sociologia das ausências e uma sociologia das emergências. Revista Crítica de Ciências Sociais, Coimbra: CES, n. 63, p. 237-280, out. 2002.

(Org.). Semear outras soluçôes: os caminhos da biodiversidade e dos conhecimentos rivais. Rio de Janeiro: Civilização Brasileira, 2005.

.; Meneses, M.P. G.; Nunes, J. A. Introdução: para ampliar o cânone da ciência: a diversidade epistemológica do mundo. In: SANTos, B. S. (Org.). Semear outras soluçôes: os caminhos da biodiversidade e dos conhecimentos rivais. Rio de Janeiro: Civilização Brasileira, 2005.

Shiva, V. Biopirataria: a pilhagem da natureza e do conhecimento. Petrópolis: Vozes, 2001.

South End Press, 2005. .; Mies, M. Ecofeminismo. Lisboa: Instituto Piaget, 1993.

Sodré, M. A verdade seduzida: por um conceito de cultura no Brasil. 3. ed. Rio de Janeiro: DP\&A, 2005.

Stallybrass, P. O casaco de Marx: roupas, memória e dor. 2. ed. Belo Horizonte: Autêntica, 2004.

Tadeu, T.; Corazza, S.; Zordan, P. Linhas de escrita. Belo Horizonte: Autêntica, 2004.

VEYNE, P. Como se escreve a história e Foucault revoluciona a história. 4. ed. Brasília: Editora Universidade de Brasília, 1998.

\section{SOBRE A AUTORA}

Rosana Medeiros de Oliveira é doutora em história pela Universidade de Brasília (UnB).

E-mail: rosanamedeirosde@gmail.com 